\title{
A new record of Metriocnemus (Inermipupa) carmencitabertarum (Orthocladiinae) from England.
}

\author{
Declan A. Murray
}

Freshwater Biodiversity, Ecology and Fisheries Research Group, School of Biology and Environmental Science, University College Dublin, Belfield, Dublin 4, Ireland.

E-mail:declan.murray@ucd.ie

Metriocnemus (Inermipupa) carmencitabertarum Langton and Cobo, 1997 was described from specimens collected by Fernando Cobo in 1989 and 1994 in Spain and Portugal (Langton and Cobo, 1997) and was subsequently reported from the Azorean islands of Terceira (Murray et al., 2004) and Santa Maria (Ramos et al. 2010). On mainland Europe, north of the Iberian Peninsula, the species was reported from the Netherlands by Kuper et al. (2012) and Kuper (2015). It is cited as being present in Estonia and Poland in Fauna Europaea, (Spies and Sæther, 2013) but these records are unconfirmed. The species was first reported in the British Isles from Somerset, England by Langton and Wilson (2012) and from County Meath in Ireland by Murray (2012). That record from England is thus far unique. However, M. carmencitabertarum is now known from nine locations in Ireland, eight, including one in Northern Ireland cited in Murray et al. (2014) and a ninth location recently reported by Murray (2016).

On a brief visit to Rufford, near Southport, Lancashire, England $\left(53.634^{\circ} \mathrm{N}, 2.823^{\circ} \mathrm{W}\right)$ on 3 November 2016, chironomid pupal exuviae were observed floating on the water surface of two outdoor disused stainless steel dog feeding/drinking bowels containing rainwater to a depth of $5.0-7.0 \mathrm{~cm}$, algae, debris and leaf litter (Fig. 1). On further examination nine exuviae and one pharate adult male were collected. The exuviae were determined as M. (I.) carmencitabertarum from Langton and Visser (2003) while the pharate adult was determined from the key in Langton (2015) to adults of the known British and Irish species of Metriocnemus. This new record from Rufford, extends the known distribution northwards in mainland Britain. All recent records are predominantly from rainwater accumulations in wheelbarrows, water butts, buckets, bird baths, dishes, discarded motor tyres etc. The species appears to be an opportunistic occupant of ephemeral habitats and because the pupal exuviae are so characteristic and easily recognisable, investigation of such anthropogenic habitats would likely lead to additional distribution records.

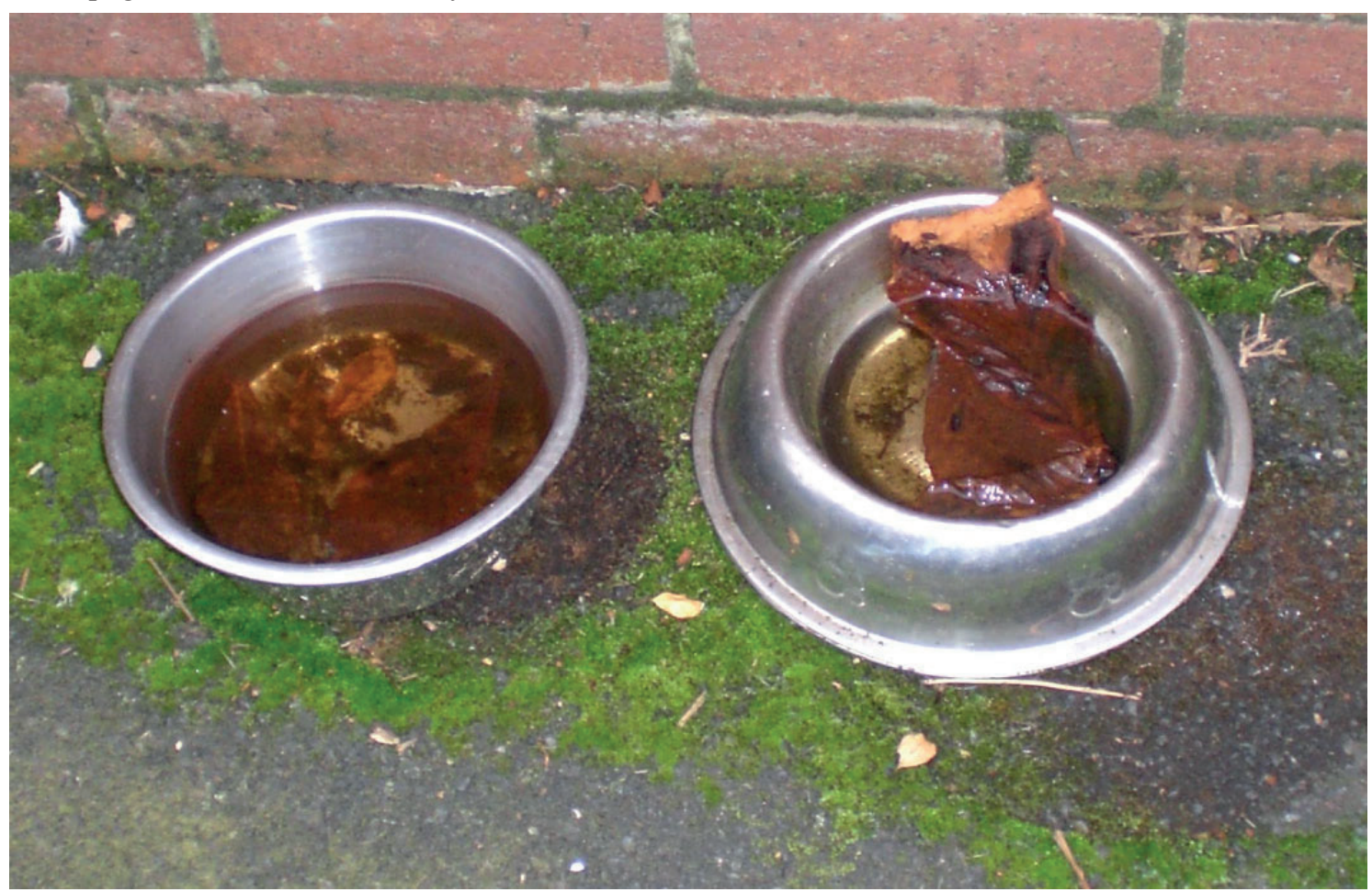

Figure1. Disused outdoor dog feeding containers with rainwater and leaf-litter from which pupal exuviae and a pharate male of Metriocnemus carmencitabertarum were collected. 


\section{References}

Kuper, J.T. 2015. Biometry of larvae and exuviae of Metriocnemus carmencitabertarum Langton and Cobo 1997 (Diptera: Chironomidae) in The Netherlands. - Lauterbornia 79: 31-36.

Kuper, J. and Moller Pillot, H. 2012. Metriocnemus carmencitabertarum, een nieuwe Dansmug voor Nederland (Diptera: Chironomidae). - Nederlandse Faunistische Mededelingen. 38: 49-54.

Langton, P. H. 2015b. Metriocnemus ephemerus sp. nov. (Diptera, Chironomidae) from Northern Ireland. - Dipterists Digest. 22: 35-42.

Langton, P. S. and Cobo, F. 1997. Metriocnemus (Inermipupa) carmencitabertarum subgen.n., sp. n. (Diptera: Chironomidae) from Spain and Portugal. - Entomologist's Gazette. 48: 263-271.

Langton, P.H and Visser, H. 2003. Chironomidae exuviae. A key to pupal exuviae of the West Palaearctic Region, Interactive System for the European Limnofauna. Biodiversity Centre of ETI. UNESCO Publishing, Paris.

Langton, P. H. and Wilson, R. S. 2012. Metriocnemus (Inermipupa) carmencitabertarum Langton and Cobo (Diptera: Chironomidae) in England. - Dipterists Digest. 19: 141.

Murray, D. A. 2012. First record for Ireland of Metriocnemus (Inermipupa) carmencitabertarum Langton and Cobo, 1997 (Diptera: Chironomidae, Orthocladiinae). - Bulletin of the Irish Biogeographical Society. $36: 3-7$

Murray, D. A. 2016. An annotated inventory of the Chironomidae (Insecta: Diptera) of County Meath, Ireland. - Bulletin of the Irish Biogeographical Society. 40: 18-42.

Murray, D.A., Hughes, S.J., Furse, M.T. and Murray, W. 2004. New records of Chironomidae (Diptera: Insecta) from the Azores, Macaronesia. - Annales de Limnologie. International Journal of Limnology. 40: $33-42$

Murray, D. A., Langton, P. H., O’Connor, J. P. and Ashe. P. 2014. Distribution records of Irish Chironomidae (Diptera): Part 2 - Orthocladiinae. - Bulletin of the Irish Biogeographical Society. 38: 61-246.

Ramos, J. Raposeiro, P.M., Cunha, A., Silva, A.A., Costa, A.C. and Gonçalves, V. 2010. Chironomidae, (Diptera: Insecta) da ihla de Santa Maria. - Relatórios e Cominições do Departamento de Biologia. 36 : 97-101.

Spies, M and Sæther, O.A. 2013. Fauna Europaea: Chironomidae. In Beuk, P. and Pape, T. (Eds.), Fauna Europaea: Diptera Nematocera. Fauna Europaea version 2.6. http:/www.faunaeur.org [accessed 30 November 2016].

Article submitted 13. December 2016, accepted by Peter H. Langton 16. December 2016, published 21. December 2016. 